\title{
Arthritis after mumps and measles vaccination
}

\author{
Moshe Nussinovitch, Liora Harel, Itzhak Varsano
}

\begin{abstract}
Measles, mumps, and rubella vaccine carries a risk of joint symptoms particularly in children under 5 years. $A$ boy who presented with an inflamed knee after measles and mumps vaccination is reported; synovial fluid aspirated from the joint contained $4 \cdot 3 \times 10^{9} / \mathrm{l}$ leucocytes. It is thought that the mumps component is the aetiological cause of acute monoarthritis. (Arch Dis Child 1995; 72: 348-349)
\end{abstract}

Keywords: arthritis, mumps measles vaccination.

Measles, mumps, and rubella vaccine has been reported to be associated with joint symptoms. ${ }^{1}$ The most likely component causing these symptoms is the rubella vaccine. Arthralgia and arthritis have not been described after infection with wild measles virus or after immunisation with measles vaccine.

A few case reports describe arthritis after infection with wild mumps virus ${ }^{2-5}$ but there are no cases described after mumps immunisation.

We present a case of acute monoarthritis with effusion after mumps and measles vaccination, which was most probably due to the mumps component. To our knowledge this is the first report of arthritis after this kind of vaccine.

\section{Case report}

Eight days after a mumps and measles vaccination was administered, a 19 month old infant developed a transient rash, a fever of $38.5^{\circ} \mathrm{C}$, and enlarged parotid glands. These signs resolved spontaneously within five days. On the 15th day after the immunisation, he presented again with a fever of $39^{\circ} \mathrm{C}$ and refusal to use his left leg. There was no history of preceding trauma.

Upon examination, his left knee was warm, tender, and swollen with decreased range of motion. The rest of the joints and general examination were normal.

The laboratory findings included a peripheral white cell count of $15.8 \times 10^{9} / 1$ and a sedimentation rate of $50 \mathrm{~mm} /$ hour; $5 \mathrm{ml}$ of turbid synovial fluid was aspirated from the joint and contained $4.3 \times 10^{9} / 1$ leucocytes. Bacterial and viral cultures were sterile, agglutination tests for Haemophilus influenzae, pneumococcus, and meningococcus antigens were negative. Attempted virus isolation from the nasopharynx or throat were negative.

There was no serological evidence of recent cytomegalovirus, Epstein-Barr virus, rubella, or mycoplasma infection. Antinuclear antibodies and rheumatoid factors were negative. Uveitis was excluded on a slit lamp examination. Radiology of both knees revealed soft tissue swelling of the left knee. Mumps antibodies (IgG) as measured one month later by complement fixation assays were $1 / 64$. Measles antibodies were $1 / 16$ (the titre normally expected after vaccination was $>1 / 8$ ).

The patient was treated with intravenous cefuroxime for five days, followed by cephalexin by mouth for another 21 days. His fever and joint symptoms subsided within 24 hours. On follow up examinations, up to three years later, he was asymptomatic.

\section{Discussion}

Many viruses are capable of causing acute arthritis in humans. Among them are rubella, parvo, herpes, enteroviruses, mumps, and others. ${ }^{6}$ Rubella associated arthropathy, rarely in both small and large joints, is the most commonly recognised virus associated arthritis in North America, after injection both of the wild virus and the vaccine.

Mumps arthritis is also well documented and may present as monoarthritis or polyarthritis, with large joints primarily affected, including knees, ankles, and hips. There is a 1-3 week interval between parotitis and the onset of arthritis. It is self limited and lasts a few days to a few weeks.

To our knowledge, arthritis after mumps immunisation has not been described in the English literature and the joint symptoms described by Benjamin et al after immunisation with measles, mumps, and rubella vaccine were attributed to the rubella component. ${ }^{1}$

This case of arthritis after vaccination against mumps and measles (without the rubella component) is to our knowledge the first report after this kind of vaccine. We believe that the mumps component is the aetiological cause of the acute monoarthritis based on: (1) the temporal relationships between the vaccination and the onset of parotitis and arthritis; (2) the serological data; and (3) ruling out other possible causes of arthritis.

It is not surprising that viral cultures were negative as no virus has yet been isolated from synovial fluid in cases of mumps arthritis. ${ }^{3}$ It is unlikely that the measles component of the vaccine caused the sort of symptoms as no one has described arthritis after infection with either wild measles virus or measles vaccine.

A long term follow up of the small numbers of children who develop arthritis will be of 
importance. Whether or not the arthritis is due to persistence of the virus or is due to an underlying condition which becomes symptomatic as a result of the virus is unclear.

1 Benjamin CM, Chew GC, Silman AJ. Joint and limb symptoms in children after immunisation with measles, mumps and rubella vaccine. $B M \mathcal{F}$ 1992; 304: 1075-8.
2 Harel L, Amir J, Reish O, et al. Mumps arthritis in children. Pediatr Infect Dis 1990; 9: 928-9.

3 Gordon SC, Lauter CB. Mumps arthritis: a review of the literature. Review of Infectious Disease 1984; 6: 338-44.

4 Scharf J, Nahir M, Dickstein G, Barzilai D. Mumps arthritis. Harefuah 1975; 89: 170-1.

5 Filpi RB, Houts RL. Mumps arthritis. $f A M A$ 1968; 205: 468-9.

6 Petty RE, Tingle AJ. Arthritis and viral infection. 7 Pediatr 1988; 113: 948-9.

\section{Iron and infants}

It seems surprising (by which I mean it surprised me) that in a country such as Canada the use of iron fortified infant formula milks is not routine. Since the late 1970 s evidence that iron deficiency has an adverse effect on infant development has steadily accumulated. Now a double blind, randomised, controlled trial in Winnipeg, Manitoba (MEK Moffatt and colleagues, Fournal of Pediatrics 1994; 125: 527-34) has shown that the use of an iron fortified formula in a socially deprived group of infants reduced the incidence of iron deficiency and improved psychomotor development at least temporarily. The subjects of the study were mainly Amerindian (or Native American') babies described as living in 'substandard housing and extreme poverty'. They were randomised to receive either iron fortified $(12.8 \mathrm{mg}$ elemental iron/l) or unfortified $(1.1 \mathrm{mg} / \mathrm{l})$ formula from within the first 2 months of life. Their haematological status and Bayley scores of development were tested at $6,9,12$, and 15 months. As expected the babies given the iron fortified milk showed less iron deficiency. Mean haemoglobin concentrations $(\mathrm{g} / \mathrm{l})$ in the fortified (unfortified) milk groups were: at 6 months, $113.5(107 \cdot 7)$; at 9 months, $116.4(111.6)$; at 12 months, $117.5(111.8)$, and at 15 months, $118.6(115 \cdot 1)$. Corresponding serum ferritin values $(\mu \mathrm{g} / \mathrm{l})$ were: 6 months, $26 \cdot 8(15 \cdot 7), 9$ months, $32 \cdot 5(11 \cdot 3)$, 12 months, $24 \cdot 0$ $(11 \cdot 3), 15$ months, $26 \cdot 1(10 \cdot 6)$. Neurodevelopmental testing showed a significant deficit in the psychomotor development index in the non-fortified milk group at 9 and 12 months $(p<0.001)$ but not at 6 or 15 months. There was no significant difference between the groups at any age for mental development index or for behaviour scores and no difference in growth or infection rates were noted.

In an accompanying editorial Lozoff (pages $577-8$ ) points out that some studies have shown developmental effects persisting for years after correction of the iron deficiency and stresses the importance of more very long term studies of performance, achievement, and problems in later life. She also points out that the mechanisms by which iron deficiency may affect development are ill understood. Although it is possible that iron deficiency could affect brain function directly, it is also possible that there could be a peripheral effect on motor performance. The fact that this and other studies have shown a greater effect of iron deficiency on motor than on mental development would be consistent with, but not proof of, a peripheral effect. The last word on iron deficiency is a long way off but meanwhile it makes no sense not to try to prevent it. 